\title{
EDUCATIONAL StANDARDS IN PRIVATE AND PUBLIC SCHOOLS
}

\author{
GIORGIO BRUNELLO \\ LORENZO ROCCO
}

\section{CESIFO WORKING PAPER No. 1418 \\ CATEGORY 4: LABOUR MARKETS \\ FEBRUARY 2005}
An electronic version of the paper may be downloaded
- from the SSRN website:
www.SSRN.com
- from the CESifo website: www.CESifo.de




\title{
EDUCATIONAL STANDARDS IN PRIVATE AND PUBLIC SCHOOLS
}

\begin{abstract}
We show that, when school quality is measured by the educational standard and attaining the standard requires costly effort, secondary education needs not be a hierarchy with private schools offering better quality than public schools, as in Epple and Romano, 1998. An alternative configuration, with public schools offering a higher educational standard than private schools, is also possible, in spite of the fact that tuition levied by private schools is strictly positive. In our model, private schools can offer a lower educational standard at a positive price because they attract students with a relatively high cost of effort, who would find the high standards of the public school excessively demanding. With the key parameters calibrated on the available micro-econometric evidence from the US, our model predicts that majority voting in the US supports a system with high quality private schools and low quality public schools, as assumed by Epple and Romano, 1998. This system, however, is not the one that would be selected by the social planner, who prefers high quality public schools combined with low quality private schools.
\end{abstract}

JEL Code: J24, H42.

Keywords: private schools, public schools, majority voting.

\author{
Giorgio Brunello \\ Department of Economics \\ University of Padova \\ Via del Santo 33 \\ 35100 Padova \\ Italy \\ giorgio.brunello@unipd.it
}

\author{
Lorenzo Rocco \\ Department of Economics \\ University of Padova \\ Via del Santo 33 \\ 35100 Padova \\ Italy \\ lorenzo.rocco@unipd.it
}

We are grateful to Sebastiano Bavetta, Daniele Checchi, Maria De Paola, David Figlio, Hideshi Itoh, Francesca Gambarotto, Luciano Greco, Eric Hanushek, Antonio Nicolò and the audiences in Padova, Siena and Tokyo (Hitotsubashi) for comments and suggestions. This paper was completed while the first author was visiting CIRJE at Tokyo University, which provided excellent hospitality. The usual disclaimer applies. 


\section{Introduction}

Do private schools always provide better service than public schools? The answer is apparently straightforward: since private schools charge a positive price (tuition), they can only attract students by providing better service than public schools, which are funded by the taxpayer (see De Fraja, 2004). Yet quality is not the only service that private schools can provide. In a recent scandal, Italian prosecutors have found that some private schools in the country used to sell high school diplomas at a price. The so called "Diploma no problem" organization provided "good service" to its customers: answers were supplied in advance for written and oral exams, and attendance records were fixed. The national exam for the leaving high school certificate was also by-passed by having customers take the exams in places where the outcome was assured (The Economist, June 12th, 2004, p.31).

In this admittedly extreme example, private schools can charge a fee by allowing customers to grab the degree with little effort: the service offered is not quality but leisure. Less extreme perhaps is the evidence discussed by Figlio and Stone, 1997, that religious private schools in the US provide lower quality in mathematics and science than public schools. In contrast, non-religious private schools are found to offer in these fields higher quality than public schools. Their evidence suggests that private schools are heterogeneous, with some offering poorer academic quality and some others offering better quality than public schools. Why do US households pay to sent their offspring to school of lower academic quality? Figlio and Stone argue that parents who enrol their offspring in private schools may care for other outcomes, such as discipline, extracurricular activities, religious matters and the opportunity to interact with a certain peer $\operatorname{group}^{1}$.

\footnotetext{
${ }^{1}$ See also McEwan, 2000. Vandenberghe and Robin, 2004, use the PISA dataset for an heterogeneous group of countries to examine the effect of private versus public education on pupils' achievement and show that private education does not generate systematic benefits. De Fraja, 2004, reports additional evidence on the UK by Marks and coauthors, who find that there is considerable variation in the quality of UK religious - and private - schools: some are very good but other are very poor. He also quotes evidence by Feinstein and Symons, 1999, who find that attendance of private schools does not affect on average individual performance
} 
In spite of this evidence, the theoretical literature - to our knowledge - does not entartain the possibility that private schools can be of lower academic quality than public schools. An important example is Epple and Romano, 1998, who model the education market as a stratified hierarchy of school qualities, with private schools doing systematically better than public schools. Schools in their model are clubs of students who differ in their academic ability, and school quality is simply the average quality of enrolled pupils. The essential reason for the existence of a hierarchy with public schools dominated by private institutions is that the latter must be of higher peer quality than the former, otherwise no student would be willing to pay to attend a private school. In their model, state schools act as residual repositories, taking in all those students who do not enrol in private schools.

In this paper we question the assumptions that private schools can only offer quality for a price and that state schools act as residual repositories. First, private schools can charge a positive price for leisure, access to networks or for religious education. Second, the assumption that public schools are of the poorest quality is both not always consistent with the stylized facts, at least in Europe and in Asia, and not derived from a policy decision rule, be it the maximization of a social welfare function or a political equilibrium based on majority voting.

We consider a simplified market for education with a sequential structure. In the first stage of the sequential game, the government decides the quality standard of the public school, which charges no admission fees. As in Costrell, 1994, quality is higher when the educational standard required to attain the degree is higher. The decision criterion used by the government is majority voting. We believe that this is an appealing and intuitive criterion for the US system of primary and secondary education (see Fernandez and Rogerson, 1995), where individuals vote on the level of education provision in their district and

in the UK. Finally, Hanushek, 2002, argues that "..it seems natural to believe that Catholic schools also exhibit wide variation in performance, although none of the existing analyses document either the magnitude or the potential causes of such differences." (p.74) 
on the associated local property taxation. We are aware, however, that there are other possible decision rules, such as welfare maximization (see De Fraja, 2002). Therefore, in the paper we also compare the outcome of majority voting with the choice by a social planner who maximizes a utilitarian welfare function.

In the second stage, a private school enters the market and chooses both the positive tuition fee and its own educational standard, which could be above or below the standard set by the public school. The private school maximizes profits by taking into account that its choice of price and standard affects the demand for its services. Profit maximization is an assumption used in most of this literature, see for instance Stiglitz, 1974, and Epple and Romano, $1998^{2}$. By restricting entry to a single private school, we focus on the relative quality of public and private schools at the cost of overlooking the heterogeneity of private schools. We feel that the treatment of this heterogeneity is important but would require a separate paper.

We define an equilibrium in this economy as the combination of the public and private school educational standards and the nonnegative tuition fee set by the private school which satisfy both majority voting and profit maximization. We show that, conditional on the standard chosen by the public school, there are three possible equilibria: a) public school quality is strictly lower than a threshold value and the private school selects a higher quality standard; b) public school quality is above the threshold and the private school selects a lower quality than the public school; c) non entry by the private school.

While case a) is consistent with Epple and Romano's story, cases b) and c) are not. In particular, case b) produces a hierarchy with private schools providing lower quality than public schools. We calibrate the key parameters of the model by using empirical evidence from the US and find an interesting contrast between majority voting and welfare maximization: while the former selects a public school of low quality and a private school of high quality, the latter selects the opposite, a public school of better quality than the private

\footnotetext{
${ }^{2}$ According to Minter Hoxby, 2000, this assumption fits well Edison and charter schools in the US. She argues that the key difference between non-profit and for-profit schools is the distribution of surplus.
} 
school. We believe that in the US system this difference arises because the majority of voters send their offspring with relatively low ability either to the public school or to no school at all. For these households, the marginal return to a higher educational standard in the public school is more than offset by the higher effort cost of attaining the standard and by the higher tax burden. Therefore, they vote for a low quality public school. The social planner, on the other hand, gives the same weight to all voters, including those of high ability and low income, who favor a higher educational standard in the public school, and therefore chooses a higher standard for the public school than the majority of voters.

The possibility that in equilibrium private schools offer lower quality than public schools has potentially important implications for education policy. Take vouchers, for instance. A voucher paid out of taxpayer money by the national or local government to households enrolling their offspring in private schools can be justified on efficiency grounds if these schools provide better quality to individuals, who could not afford the price in the absence of the subsidy. Justification is harder, however, if the taxpayer's money is spent to finance vouchers paid out to households who enrol their children in private schools of low quality.

The paper is organized as follows. Section 2 introduces the model. Section 3 discusses household demand of private and public education and Section 4 deals with the behavior of the private school. Next, Section 5 is devoted to majority voting and Section 6 to the decision taken by the social planner. Calibration is discussed in Section 7. Conclusions follow.

\section{The Model}

We consider an economy where high school education is provided either by a single public school or by the combination of a public and a private school. Entry by schools is sequential and the timing of the model is as follows: in the first stage the government decides the educational standard of the public school; 
in the second stage, a private school decides entry, tuition and educational standard; in the third and final stage households enroll their offspring in one of the available schools.

The government sets up the public school and selects the educational standard $s_{G} \in[1,2]$. As in Costrell, 1994, the standard is the productivity level to graduate. The underlying idea is that the student's future productivity in the workplace is "..governed by the cognitive and social skills acquired in school, by dint of hard work.." (Costrell, 1994, p.958). The higher the standard, the more substantive the acquired skills and the harder the work required to attain it. We find it natural to interpret the educational standard as a measure of school quality. A higher standard is more costly to the school because it requires better teachers and facilities such as labs and libraries. Let $k \in[0,1]$ be the unit cost of setting the standard $s_{G}$. This cost is funded by a proportional tax paid by all households, independently of whether they send their offspring to the public high school or not. Since attaining the standard requires effort, and individuals differ in innate ability, not all the pupils in this economy complete high school ${ }^{3}$.

The private school decides whether to enter in the market for high school education and, conditional upon entry, chooses the standard $s_{P}$ and the price $p$ to maximize (expected) profits ${ }^{4}$. Its profit function is

$$
\pi=p D-k s_{P}
$$

where $D$ is expected demand and the unit cost of setting the standard does not vary with the type of school. Once the educational standard has been set, the marginal costs of supplying school services are assumed to be zero ${ }^{5}$. Profits are positive in the event of entry and equal to zero in the event of no entry.

Each household in this economy consists of a mother and a daughter. The household utility function is linear in $y \in[0,1]$, the exogenous income of the

\footnotetext{
${ }^{3}$ The dropout rate of young Americans - aged 16 to 24 - from high school was $10.9 \%$ in 2000.

${ }^{4}$ Profit maximization is an assumption used in most of this literature, see for instance Stiglitz, 1974, and Epple and Romano, 1998. According to Minter Hoxby, 2000, this assumption fits well Edison and charter schools in the US. She argues that the key difference between non-profit and for-profit schools is the distribution of surplus.

${ }^{5}$ Positive marginal costs complicate the algebra without providing further insights.
} 
mother, and concave in $w$, the earnings of the daughter, a useful simplification in line with the relevant literature - see De Fraja, $2002^{6}$. The mother can use endowed income $y$ for consumption, to pay income taxes and to fund the daughter's costs of schooling in the event she enrols in the private school. We exclude liquidity constraints by assuming that each household can freely borrow against the future income of the offspring $w$. The discount factor is equal to 1 . Daughters are heterogeneous and individual differences are described by the pair $(\theta, y)$ where $\theta \in[0,1]$ is an inverse measure of ability, lower for higher ability. We assume that $\theta$ and $y$ are independently and uniformly distributed ${ }^{7}$.

Household utility $U$ is

$$
U=y(1-\tau)-p+\ln w(e, s, \theta, y)-\theta s
$$

where $e$ is a dummy equal to 1 if the daughter completes high school and to 0 otherwise $^{8}, s=s_{G}, s_{P}, p$ is the tuition fee - zero in the public school and positive in the private school - and $\theta s$ is the effort cost of attaining the educational standard $s$ : the higher the standard, the higher the effort required to attain it, but the effort cost is lower the higher is innate ability ${ }^{9}$.

A key finding of the empirical labor economics literature since Mincer - see for instance Blackburn and Neumark, 1993, Murnane, Willett and Levy, 1995, Bowles, Gintis and Osborne, 2001, Altonji and Pierret, 2001, and Hanushek and Kimko, 2000 - is that earnings are a log-linear function of individual characteristics, including school quantity and quality. Drawing from this literature, we specify the daughter's earnings as follows

$$
\ln w(e, s, \theta, y)=\left(\lambda_{0}+\lambda_{1} s\right) e+\lambda_{2} \theta+\lambda_{3} y+\lambda_{4} X
$$

\footnotetext{
${ }^{6}$ In De Fraja the household utility function is concave in the mother's consumption and linear in the daughter's income.

${ }^{7}$ This assumption significantly improves the tractability of the model.

${ }^{8}$ High school completion is a ticket for college education. While we do not directly consider college education, we do so indirectly, because graduation from a high quality secondary school is expected to increase enrolment in a high quality college.

${ }^{9}$ Linear costs of effort generate corner solutions for the educational standard. Since we are mainly interested in the relative standard of the private and public school, this is a useful simplification.
} 
where the constant term $\lambda_{0}$ captures the gains associated to the attained high school degree, $\lambda_{1}$ is the labor market return to school quality - measured by the educational standard $s-\lambda_{2}$ and $\lambda_{3}$ are the returns to individual ability and family income and $X$ is a vector of residual individual characteristics. The empirical earnings function (3) suggests that the labor market recognizes both the quantity and the quality of education. Based on the empirical findings for the US - reviewed in detail in Section 7 of the paper - we restrict the key parameters of the earnings function as follows

$$
\lambda_{0} \in[0,1] \quad \lambda_{1} \in[0,1] \quad \lambda_{0}+\lambda_{1}<1
$$

The sequential structure of the model suggests that we solve it by backward induction. Therefore, we start by characterizing the enrolment decision of households.

\section{Household choice}

When high school education is provided by a public and a private school, student $i$ prefers to enrol in the private school if

$$
U_{i}\left(s_{P}\right)>U_{i}\left(s_{G}\right)
$$

which yields - using (2) and (3) - the following separating condition

$$
\theta^{*}=\lambda_{1}-\frac{p}{s_{P}-s_{G}}
$$

If $s_{P}>s_{G}$, students with $\theta_{i}>\theta^{*}$ - who have lower innate ability - enrol in the public school and students with $\theta_{i}<\theta^{*}$ - who have high ability - go to the private school. On the other hand, if $s_{P}<s_{G}$, students with $\theta_{i}>\theta^{*}$ prefer the private school and the complementary group goes to the public school.

Independently of whether the private or the public school are selected, enrolment requires that expected utility be higher than the reservation level of utility, given by $\bar{U}=y(1-\tau)+\lambda_{2} \theta+\lambda_{3} y+\lambda_{4} X$. This level says that failure to graduate from upper secondary education reduces both log earnings - by $\lambda_{0}+\lambda_{1} s-$ and the monetary (for the private school) and effort costs of attaining the degree. 
Condition (6) clarifies that the private school has no incentive to set the standard at the same level of the public standard, because with a positive price it would attract no student. It also shows that household demand for the private school depends on whether the latter sets a higher or a lower educational standard than the public school. There are two regimes and we consider them in turn.

\subsection{Regime 1: entry with a standard higher than $s_{G}$}

Let the standard $s_{P}$ be higher than $s_{G}$. In this case the separating condition is (6) and individuals with high ability - or $\theta<\theta^{*}$ - prefer the private to the public school. If they do so, they also prefer enrolment to no participation, because $U\left(s_{P}\right)>\bar{U}$ yields

$$
\theta<\lambda_{1}-\frac{p}{s_{P}}+\frac{\lambda_{0}}{s_{P}}
$$

which always holds for $\theta<\theta^{*}$. Individuals with lower ability - or $\theta>\theta^{*}$ - either enrol in the public school or do not enrol at all. Failure to enrol occurs if

$$
\theta>\lambda_{1}+\frac{\lambda_{0}}{s_{G}}
$$

It follows that, with a uniformly distributed random variable $\theta$, the demand faced by the private school in this regime is

$$
D=\lambda_{1}-\frac{p}{s_{P}-s_{G}}
$$

\subsection{Regime 2 : entry with a standard lower than $s_{G}$}

Let the standard $s_{P}$ be lower than $s_{G}$. In this case the separating condition becomes

$$
\theta^{*}=\lambda_{1}+\frac{p}{s_{G}-s_{P}}
$$


Conditional on the selection of the private school, participation requires

$$
\theta<\lambda_{1}+\frac{\lambda_{0}-p}{s_{P}}
$$

and the demand for private school services is

$$
D=\frac{\lambda_{0}-p}{s_{P}}-\frac{p}{s_{G}-s_{P}}
$$

This demand is positive if

$$
p<\lambda_{0} \frac{s_{G}-s_{P}}{s_{G}}
$$

Therefore, the higher the (percentage) difference in the educational standard between the public and the private school the higher the tuition fee that the private school can set and still attract a positive demand for its services ${ }^{10}$.

\section{The choice of the price and the standard by the private school}

Since the distribution of pupils between schools depends on whether the private school selects a standard higher or lower than $s_{G}$, we need to distinguish two separate cases, $s_{P}>s_{G}$ and $s_{P}<s_{G}$. Consider first the case $s_{P}>s_{G}$ and let the profits of the private school be $\pi_{H}=p D_{H}-k s_{P}$, where $D_{H}=\lambda_{1}-\frac{p}{s_{P}-s_{G}}$. Profit maximization yields the following first order conditions

$$
\frac{\partial \pi_{H}}{\partial s_{P}}=\frac{p^{2}}{\left(s_{P}-s_{G}\right)^{2}}-k \geq 0
$$

and

$$
\frac{\partial \pi_{H}}{\partial p}=\lambda_{1}-\frac{2 p}{\left(s_{P}-s_{G}\right)}=0
$$

from which we get

$$
p=\frac{\left(s_{P}-s_{G}\right) \lambda_{1}}{2}
$$

which implies that the demand for private school services (9) is positive for each educational standard $s_{P}>s_{G}$. The optimal price increases in the standard $s_{P}$

\footnotetext{
${ }^{10}$ The condition for no enrolment in this regime is (8), as in the previous regime.
} 
and decreases in the standard set by the public school. By substituting equation (14) into condition (12), we get

$$
s_{P}=2
$$

provided that

$$
\lambda_{1}^{2}>4 k
$$

The latter condition says that a high quality private school exists only if the marginal benefit of a higher educational standard is significantly superior to the marginal cost ${ }^{11}$.

Upon substitution, the optimal profit is

$$
\pi_{H}=\frac{\lambda_{1}^{2}\left(2-s_{G}\right)}{4}-2 k
$$

Since $\frac{\partial \pi_{H}}{\partial s_{G}}<0$, we define $\bar{s}_{G}=2\left(1-\frac{4 k}{\lambda_{1}^{2}}\right)$ as the maximum value of $s_{G}$ for which $\pi_{H} \geqslant 0$ holds. For $s_{G}>\bar{s}_{G}$ we have $\pi_{H} \equiv 0$ and no entry ${ }^{12}$. Whilst (16) implies that $\bar{s}_{G}$ is lower than 2 (the maximum feasible standard), $\bar{s}_{G}>1$ requires that $\lambda_{1}^{2}>8 k$.

Next consider the case $s_{P}<s_{G}$ and let the profits of the private school be $\pi_{L}=p D_{L}-k s_{P}$, where $D_{L}=\frac{\lambda_{0}}{s_{P}}-\frac{p s_{G}}{s_{P}\left(s_{G}-s_{P}\right)}$. Profit maximization yields

$$
\frac{\partial \pi_{L}}{\partial s_{P}}=-p\left[\frac{\lambda_{0}}{s_{P}^{2}}+p s_{G}\left(\frac{1}{s_{P}\left(s_{G}-s_{P}\right)^{2}}-\frac{1}{s_{P}^{2}\left(s_{G}-s_{P}\right)}\right)\right]-k<0
$$

since $\frac{1}{s_{P}\left(s_{G}-s_{P}\right)^{2}}-\frac{1}{s_{P}^{2}\left(s_{G}-s_{P}\right)}>0$. Therefore the optimal standard in this case is $s_{P}=1$.

The first order condition with respect to $p$ is

$$
\frac{\partial \pi_{L}}{\partial p}=\frac{\lambda_{0}}{s_{P}}-\frac{2 p s_{G}}{s_{P}\left(s_{G}-s_{P}\right)}=0
$$

from which we get

$$
p=\frac{1}{2} \frac{\lambda_{0}\left(s_{G}-1\right)}{s_{G}}
$$

The optimal profit of the private school can be written as

\footnotetext{
${ }^{11}$ This condition implies $\lambda_{1}>2 k$.

${ }^{12}$ Profits cannot be negative, because in this case the private school prefers no entry.
} 


$$
\pi_{L}=\frac{\lambda_{0}^{2}\left(s_{G}-1\right)}{4 s_{G}^{2}}-k
$$

Since $\frac{\partial \pi_{L}}{\partial s_{G}}>0$ within the interval $[1,2]$, we define $\underline{s}_{G}=\frac{\left.1-\sqrt{1-4 \frac{4 k}{\lambda_{0}^{2}}}\right)}{2 \frac{4 k}{\lambda_{0}^{2}}}$ as the minimum value of $s_{G}$ for which $\pi_{L} \geqslant 0$ holds. When $s_{G}<\underline{s}_{G}$, profits $\pi_{L} \equiv 0$ and the private school does not enter. The threshold $\underline{s}_{G}$ exists only if $\lambda_{0}^{2}>16 k$ and in such a case it always belongs to the interval $[1,2]$. If this condition is violated, the private school never finds it profitable to choose a low educational standard.

In summary, only when conditions $\lambda_{1}^{2}>8 k$ and $\lambda_{0}^{2}>16 k$ are both satisfied does the private school have two available options - high or low educational standard. In this case, $\bar{s}_{G}>\underline{s}_{G}$ if

$$
\lambda_{0}^{2}>\frac{16 k\left(\lambda_{1}^{2}-4 k\right)^{2}}{\lambda_{1}^{2}\left(\lambda_{1}^{2}-8 k\right)}
$$

Since $\frac{\left(\lambda_{1}^{2}-4 k\right)^{2}}{\lambda_{1}^{2}\left(\lambda_{1}^{2}-8 k\right)}>1$, the above condition is stronger than $\lambda_{0}^{2}>16 k$. Therefore we have

$$
\bar{s}_{G}>\underline{s}_{G} \quad \text { if } \quad \lambda_{1}^{2}>8 k \quad \text { and } \quad \lambda_{0}^{2}>\frac{16 k\left(\lambda_{1}^{2}-4 k\right)^{2}}{\lambda_{1}^{2}\left(\lambda_{1}^{2}-8 k\right)}
$$

\subsection{The choice of the standard above or below $s_{G}$}

We have derived the optimal tuition fee and educational standard of the private school in two separate regimes, when the standard is respectively higher and lower than the standard of the public school. Next we determine how the private school selects the best regime. Noticing that, at the optimal pricing policy, the profit functions (17) and (19) depend on the standard set by the government for public schools, $s_{G}$, we establish the following propositions:

Proposition 1 Suppose that $\underline{s}_{G}<\bar{s}_{G}$. Then there exists a unique value $\underline{s}_{G}<$ $s_{G}^{*}<\bar{s}_{G}$ such that the private school chooses a standard below $s_{G}$ for any $s_{G}>s_{G}^{*}$ and a standard above $s_{G}$ for any $s_{G}<s_{G}^{*}$ 


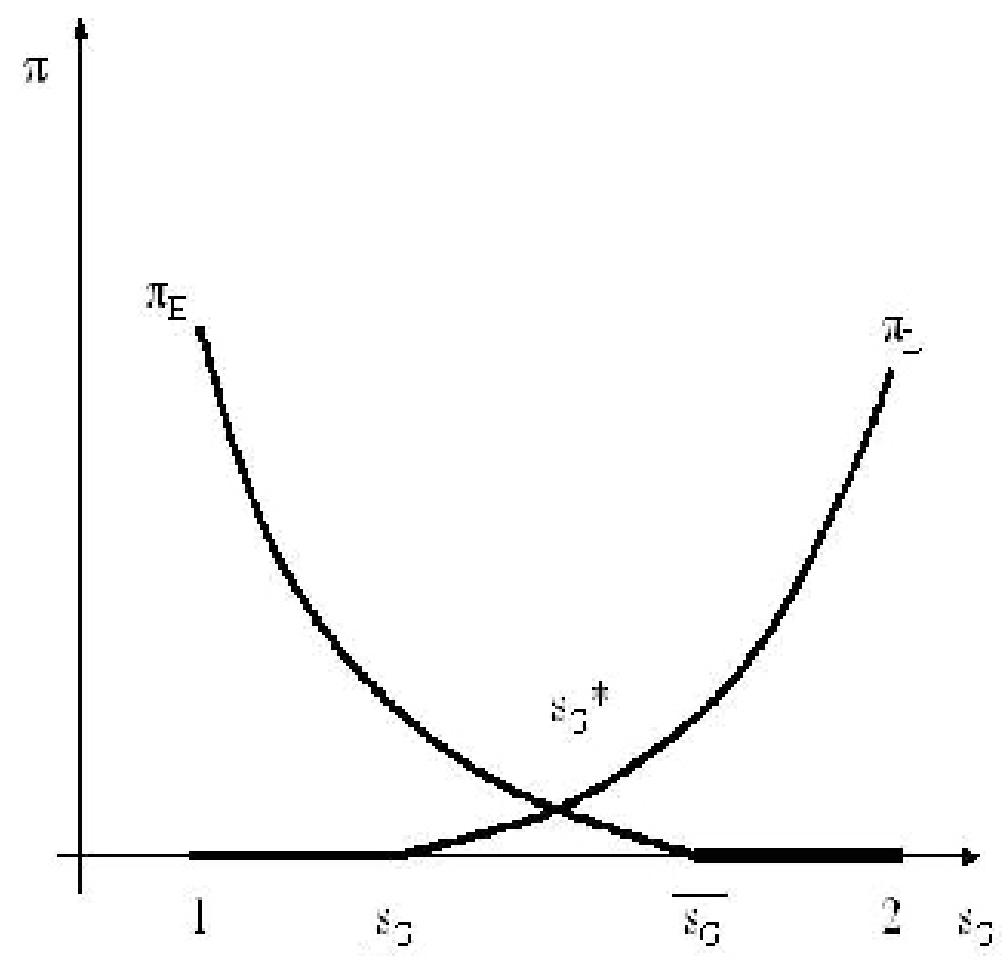

Figure 1: Proposition 1

Proof. See Appendix.

Figure 1 illustrates the intersection of the profit functions $\pi_{H}$ and $\pi_{L}$ when $\underline{s}_{G}<\bar{s}_{G}$.

Proposition 2 Suppose that $\underline{s}_{G}>\bar{s}_{G}$. Then for $\bar{s}_{G}<s_{G}<\underline{s}_{G}$ the private school always makes negative profits and refrains from entering the education market. For $s_{G}<\bar{s}_{G}$ the private school chooses high quality and for $s_{G}>\underline{s}_{G}$ it chooses low quality

Proof. See Appendix 


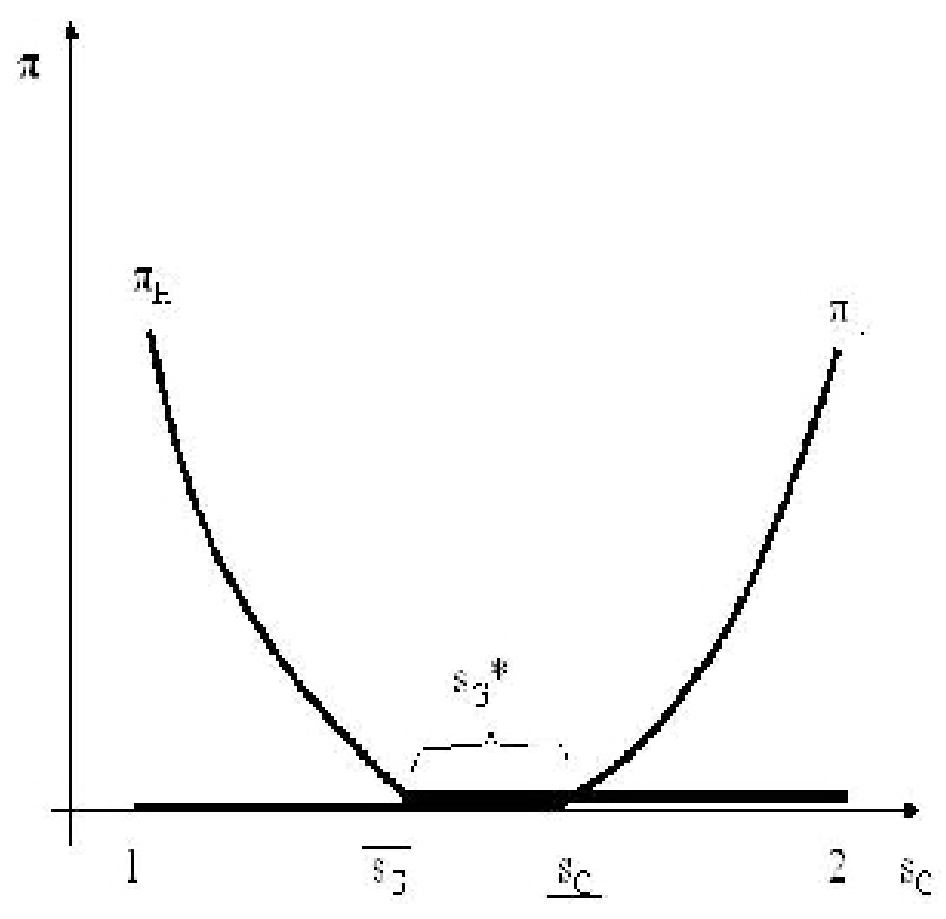

Figure 2: Proposition 2

Figure 2 illustrates the case of Proposition 2. The two propositions show that, if the private school enters the education market, it chooses either a higher or a lower educational standard than the public school. If it chooses a higher standard, it sets it to the maximum feasible value. If it chooses a lower standard, it sets it to the minimum feasible value ${ }^{13}$. In spite of the fact that households always pay positive tuition fees for private education, only the former case corresponds to the hierarchical model of Epple-Romano, 1998, where the public school is of lower quality than the private school.

\footnotetext{
${ }^{13}$ The choice of the extreme values is dictated by the assumption that the costs of attaining the standard in the individual utility function are linear in the standard.
} 
The choice of the standard by the private school depends crucially on the standard selected by the public school. Independently of the selected regime, private tuition is a function of the distance between the public and the private standard. Suppose that the government sets a low standard for the public school. In this case, the private school can charge a high price by choosing a high educational standard. As the standard in the public school increases, however, the relative convenience that the private school has of setting a high standard declines, and after a given threshold $-s_{G}^{*}$ - the private school finds it more profitable to switch to a low standard. By so doing, it can increases both tuition and profits ${ }^{14}$.

The type of equilibrium which prevails depends critically on government choice. The government chooses the educational standard of the public school by taking into account the subsequent entry of the private school. We turn to this decision in the next section of the paper.

\section{The choice of the standard for the public school: majority voting}

In the previous section we have shown that the private school can choose an educational standard either above or below the standard selected by the public school, provided that some restrictions on the relevant parameters hold. In this section we assume this to be the case. Later on we briefly consider what happens in the model when the private school can only enter with a high standard $\left(\lambda_{0}^{2}<\right.$ $16 k)$ or with a low standard $\left(\lambda_{1}^{2}<8 k\right)$. Furthermore, the characterization of government choice requires that we distinguish between equilibria when $\underline{s}_{G}<\bar{s}_{G}$ and equilibria when $\underline{s}_{G}>\bar{s}_{G}$. In this section we only examine government choice when $\underline{s}_{G}<\bar{s}_{G}$, and sketch the case $\underline{s}_{G}>\bar{s}_{G}$, which is very similar, in the Appendix.

We start by assuming that the public sector budget, which consists only of

\footnotetext{
${ }^{14}$ At the optimal price and private standard, the demand for private schools is a constant, and so is the total cost of setting the standard. Therefore, profits vary only with private tuition $p$.
} 
educational expenditures and income taxes, is always balanced. This is equivalent to requiring

$$
\int_{0}^{1} \tau y d y=k s_{G}
$$

which yields, upon integration

$$
\tau=2 k s_{G}
$$

Therefore, a higher educational standard increases the proportional tax rate paid by all the households in this economy.

We posit that the choice of the public school standard $s_{G}$ is based on majority voting - as in Stiglitz, 1974, and Fernandez and Rogerson, 1995 - and describe the outcome of the voting as follows: first, we select the value of $s_{G}$ preferred by the majority of households in each of the two regimes - the private school with lower and higher standard than the public school respectively. Second, we compare preferred outcomes across regimes and choose the one favored by the majority of voters.

\subsection{Regime 1: high quality public school $\left(s_{G}>s_{G}^{*}\right)$}

In the regime $s_{G}>s_{G}^{*}$ the private school chooses $s_{P}=1$ and $p=\frac{1}{2} \frac{\lambda_{0}\left(s_{G}-1\right)}{s_{G}}$. Let $U_{P}$ and $U_{G}$ be the utilities of going to the private and public school respectively. We ask how these utilities vary with the public standard $s_{G}$. It turns out that

$$
\frac{\partial U_{P}}{\partial s_{G}}=-2 k y-\frac{1}{2} \frac{\lambda_{0}}{s_{G}^{2}}<0 \rightarrow s_{G}=s_{G}^{*}
$$

for individuals enrolled in the private school. Since the derivative is negative, households with students in private schools unambiguously prefer the lowest value of $s_{G}$ in the regime, $s_{G}^{*}$. On the other hand

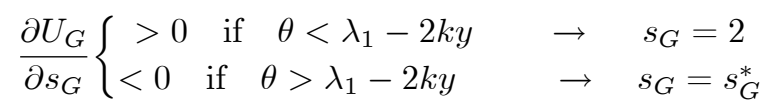

for individuals enrolled in the public school. More able students, for whom the derivative is positive, profit from a higher public standard and vote for $s_{G}=2$, and less able individuals, for whom the derivative is negative, gain from a lower standard, and vote for $s_{G}=s_{G}^{*}$. We establish the following 
Lemma 3 If the group of individuals with $\theta<\lambda_{1}-2 k y$ is the majority, majority voting yields $s_{G}=2$. If the group with $\theta>\lambda_{1}-2 k y$ is the majority, it chooses $s_{G}=s_{G}^{*}$.

Proof. See the Appendix

As shown in Figure 4 in the Appendix, the group with $\theta<\lambda_{1}-2 k y$ - area $\mathrm{D}$ in the figure - enrols in the public school and is composed of high ability individuals, who can attain a high educational standard with relatively low cost of effort. While only the very able vote for a high educational standard in the public school independently of their household income, the not so able and poor also favor high quality in the public school, because the marginal benefit is high relative to the cost, which is proportional to their low income.

\subsection{Regime 2: low quality public school $\left(s_{G}<s_{G}^{*}\right)$}

In the regime $s_{G}<s_{G}^{*}$, the private school selects $s_{P}=2$ and $p=\frac{\lambda_{1}\left(s_{P}-s_{G}\right)}{2}$. Using the optimal values of prices and standards in the individual utility function, we get

$$
\frac{\partial U_{P}}{\partial s_{G}}=-2 k y+\lambda_{1}>0 \text { for } \lambda_{1}>4 k \rightarrow s_{G}=s_{G}^{*}
$$

for individuals enrolled in the private school, and

$$
\frac{\partial U_{G}}{\partial s_{G}}\left\{\begin{array}{c}
>0 \text { if } \theta<\lambda_{1}-2 k y \quad \rightarrow \quad s_{G}=s_{G}^{*} \\
<0 \text { if } \theta>\lambda_{1}-2 k y \quad \rightarrow \quad s_{G}=1
\end{array}\right.
$$

for individuals in the public school. We have

Lemma 4 If the group of individuals with $\theta<\lambda_{1}-2 k y$ is the majority, majority voting yields $s_{G}=s_{G}^{*}$. If the group with $\theta>\lambda_{1}-2 k y$ is the majority, it chooses $s_{G}=1$.

Proof. See the Appendix

\subsection{The choice between regimes}


In the previous sub-sections we have shown that, if the group with $\theta<$ $\lambda_{1}-2 k y$ is the majority of the population, the optimal choice is $s_{G}=2$ when $s_{G}>s_{G}^{*}$ and $s_{G}=s_{G}^{*}$ when $s_{G}<s_{G}^{*}$. We use these results to compare regimes and establish the following

Proposition 5 If the group with $\theta<\lambda_{1}-2 k y$ is the majority, it chooses the regime $s_{G}>s_{G}^{*}$ and $s_{G}=2$. If the majority is with the group $\theta>\lambda_{1}-2 k y$, it votes for $s_{G}<s_{G}^{*}$ and $s_{G}=1$.

Proof. See the Appendix.

The group with $\theta<\lambda_{1}-2 k y$ is the majority when

$$
\frac{\lambda_{1}+\left(\lambda_{1}-2 k\right)}{2}>\frac{1}{2}
$$

i.e. when the size of the group is larger than $50 \%$. This is equivalent to the following condition

$$
\lambda_{1}-k>\frac{1}{2}
$$

which is satisfied when the difference between the marginal benefit of the educational standard, $\lambda_{1}$, and the marginal cost, $k$, is higher than $\frac{1}{2}$. Figure 3 shows the combinations of the two parameters for which the private school has either a lower or a higher educational standard than the public school. Both areas are above the concave curve $\lambda_{1}^{2}-8 k=0$. In this portion of the figure, values of $\lambda_{1}$ above the line $\lambda_{1}=\frac{1}{2}+k$ - area $\mathrm{A}$ - identify equilibria where the educational standard of the public school is highest, and values below - area D - shows equilibria where the private school has the highest standard. The next sub-section discusses what happens in the areas $\mathrm{B}$ and $\mathrm{C}$ below the concave curve.

\subsection{The public school standard with no high quality private schools}

If the restriction $\lambda_{1}^{2}>8 k$ does not hold, a private school with a high educational standard is not profitable. Therefore, $s_{P}<s_{G}$ and the private standard 


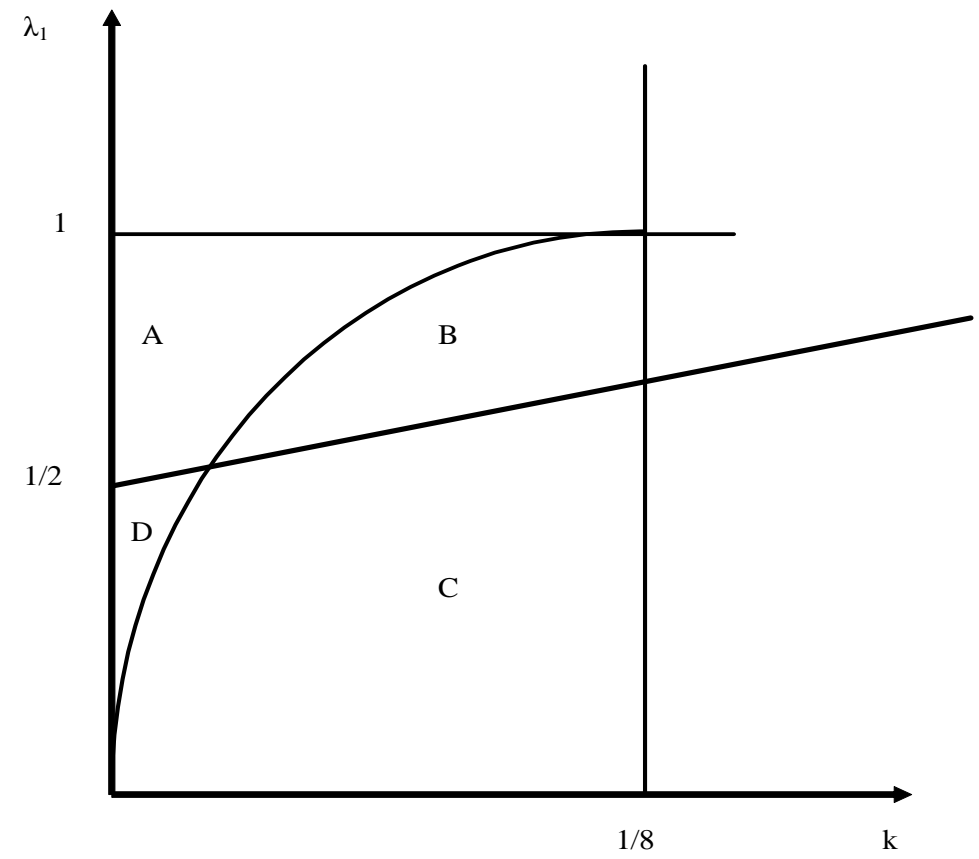

Figure 3: Combinations of $\lambda_{1}$ and $k$ 
is $s_{P}=1$ if $s_{G}>\underline{s}_{G}$. When $s_{G}<\underline{s}_{G}$ only the public school remains in the market. We show in the Appendix that the outcome described by Proposition 5 still holds, with the exception that, when the quality of the public school is low, there is no private school.

If $\lambda_{1}-k>\frac{1}{2}$ - area $\mathrm{B}$ in Figure 3 - the voting outcome is $s_{G}=2$ (which implies $s_{P}=1$ ). On the other hand, if $\lambda_{1}-k<\frac{1}{2}$ - area $\mathrm{C}$ in Figure 3 - then $s_{G}=1$, and there is no private school ${ }^{15}$.

\subsection{The public school standard with no low quality private schools}

Finally consider the case when $\lambda_{1}^{2}>8 k$ but $\lambda_{0}^{2}<16 k$. Under these conditions the private school finds it profitable to enter only by providing a high standard. Therefore $s_{P}=2$ if $s_{G}<\bar{s}_{G}$ and there is no private school if $s_{G}>\bar{s}_{G}$. The characterization of the public school standard follows the discussion in the previous sub-section and is briefly sketched in the Appendix. It turns out that, if the majority condition $\lambda_{1}-k>\frac{1}{2}$ holds, the voting outcome is $s_{G}=2$, a school system characterized by an excellent public school with no private school prevails. Conversely, if $\lambda_{1}-k<\frac{1}{2}$, then $s_{G}=1$.

\section{The choice of the standard for the public school: the social planner}

In the previous section we have applied a "political economy" approach to the determination of the educational standard of the public school. In this approach, households vote on the quality of education provision - measured by the educational standard - and take into account that a higher public quality needs to be financed with higher income taxes. While this approach captures in a broad way the local finance mechanism for the provision of primary and secondary education in the US, it is not necessarily the appropriate model for

\footnotetext{
${ }^{15}$ This is so even when $\lambda_{1}-2 k<0$, because the cost of the educational standard in the public school is too high.
} 
the rest of the world. In many other countries, education policies are set nationally by the central or regional government, and an alternative approach to the determination of the educational standard of the public school is that the government chooses this standard, and income taxes, to maximize a utilitarian welfare function (De Fraja, 2002).

In this section, we characterize the market for education when the government acts as a social planner, and contrast the results with the findings obtained from the "political equilibrium" approach. We assume that the welfare function used by the government is utilitarian - the simple aggregation of the utilities of all the households in the economy ${ }^{16}$. Moreover, we limit our attention to the case $\underline{s}_{G}<\bar{s}_{G}$. As above, we need to distinguish between two regimes, $s_{G}>s_{G}^{*}$ and $s_{G}<s_{G}^{*}$. For each regime, we compute the optimal choice of the educational standard. Next, we compare optimal choices across regimes and choose the regime which maximizes the social welfare function.

\subsection{Regime 1: the private school sets a low standard}

When $s_{G}>s_{G}^{*}$, the private school sets $s_{P}=1$ and $p=\frac{\lambda_{0}\left(s_{G}-1\right)}{2 s_{G}}$. In this case the social welfare function is

$W_{L}=\int_{y}\left[\int_{0}^{\lambda_{1}+\frac{\lambda_{0}}{2 s_{G}}} U_{G}\left(s_{G}, \theta, y\right) d \theta+\int_{\lambda_{1}+\frac{\lambda_{0}}{2 s_{G}}}^{\lambda_{1}+\frac{\lambda_{0}\left(s_{G}+1\right)}{2 s_{G}}} U_{P}\left(s_{G}, \theta, y\right) d \theta+\int_{\lambda_{1}+\frac{\lambda_{0}\left(s_{G}+1\right)}{2 s_{G}}}^{1} \bar{U}(y) d \theta\right] d y$

and its first derivative with respect to $s_{G}$ is

$$
\frac{\partial W_{L}}{\partial s_{G}}=\left(-k+\frac{\lambda_{1}^{2}}{8}\right)+\frac{3}{8}\left(\lambda_{1}^{2}-\frac{\lambda_{0}^{2}}{s_{G}^{2}}\right)
$$

The sign of this derivative cannot be determined in an unambiguous way, but is certainly positive if $\lambda_{1}>\lambda_{0}$. In this special case, the optimal choice of the

\footnotetext{
${ }^{16}$ In so doing, the government is assumed to assign zero weight to the profits of the private school. Nothing of substance changes if we remove this assumption.
} 
educational standard is $s_{G}=2 .{ }^{17}$

\subsection{Regime 2: the private school selects a high stan- dard}

When $s_{G}<s_{G}^{*}$, the private school sets $s_{P}=2$ and $p=\frac{\lambda_{1}\left(2-s_{G}\right)}{2}$, and the social welfare function is

$$
W_{H}=\int_{y}\left[\int_{0}^{\frac{\lambda_{1}}{2}} U_{P}\left(s_{G}, \theta, y\right) d \theta+\int_{\frac{\lambda_{1}}{2}}^{\lambda_{1}+\frac{\lambda_{0}}{s_{G}}} U_{G}\left(s_{G}, \theta, y\right) d \theta+\int_{\lambda_{1}+\frac{\lambda_{0}}{s_{G}}}^{1} \bar{U}(y) d \theta\right] d y
$$

with first derivative

$$
\frac{\partial W_{H}}{\partial s_{G}}=\left(-k+\frac{1}{8} \lambda_{1}^{2}\right)+\frac{1}{2}\left(\frac{\lambda_{1}^{2}}{2}-\frac{\lambda_{0}^{2}}{s_{G}^{2}}\right)
$$

which again cannot be unambiguously signed. If $\lambda_{1}>2 \lambda_{0}$, however, the sign is positive and the optimal government choice is $s_{G}^{*}{ }^{18}$.

In summary, the social planner's choice of the standard depends critically on the parameters of the earnings function $\lambda_{0}$ and $\lambda_{1}$. Therefore, in the next section we calibrate these parameters by using micro-econometric evidence from the US.

\section{Calibration}

The earnings function (3) postulates that individual earnings increase both in the quantity of education and in the level of the educational standard. More education increases individual human capital. A higher standard increases individual proficiency in cognitive skills, which shows up in higher test scores ${ }^{19}$. In a well known study, Murnane, Willett and Levy, 1995, use data from the US

\footnotetext{
${ }^{17}$ Since the second derivative is clearly positive, the welfare function is convex in $s_{G}$, with a minimum given by $s_{G}^{\min }=\frac{3 \lambda_{0}}{2 \sqrt{3 \lambda_{1}^{2}-6 k}}$.

${ }^{18}$ Again, the welfare function is convex in $s_{G}$, with a minimum at $s_{G}^{\min }=\frac{2 \lambda_{0}}{\sqrt{3 \lambda_{1}^{2}-8 k}}$.

${ }^{19}$ We thank without implicating Eric Hanushek for suggesting this approach.
} 
High School and Beyond survey and measure accumulated cognitive skills with the scores in the mathematics test administered in the last year of high school. They estimate individual earnings functions separately for males and females and obtain that the marginal return to a year of education is 0.021 for males and 0.037 for females. They also find that the marginal return to the test score is 0.011 for males and 0.017 for females. Since high school lasts three years, these estimates imply that $\lambda_{0}=0.063$ for males and $\lambda_{0}=0.111$ for females. To calibrate $\lambda_{1}$ we need to rescale the test score variable so that it lies between 1 and 2. If we do so, we obtain $\lambda_{1}=0.317$ for males and $\lambda_{1}=0.439$ for females ${ }^{20}$.

Interestingly, these estimates are not far from those obtained by Blackburn and Neumark, 1993, who also use the NLSY and measure cognitive skills with the results of the ASVAB test. According to our calculations, the values of $\lambda_{0}$ and $\lambda_{1}$ implied by their estimates are 0.093 and 0.318 respectively. Finally, Altonji and Pierret, 2001, use the AFQT test scores - a subset of the ASVAB tests - to measure cognitive abilities and estimate an earnings function similar to (3). It turns out that the values of $\lambda_{0}$ and $\lambda_{1}$ associated to their estimates are 0.170 and 0.390 respectively.

We take the values of the parameters from the latter study to evaluate the social planner's choice, and let $k$ take any value which satisfies $\underline{s}_{G}<\bar{s}_{G}$. Since $\lambda_{1}>2 \lambda_{0}$, we conclude that the optimal choice of the educational standard by the social planner is $s_{G}=2$ if $s_{G}>s_{G}^{*}$ and $s_{G}^{*}$ if $s_{G}<s_{G}^{*}$. Next, we compare the values of the social welfare function across the two regimes and find that, when the parameters assume their calibrated values, $W_{L}\left(s_{G}=2\right)>W_{H}\left(s_{G}=s_{G}^{*}\right)$, and $s_{G}=2$ is the educational standard which attains the global maximum.

Notice the contrast between the optimal standard selected by the social planner and the standard selected by majority voting. Since the condition $\lambda_{1}-$ $k>\frac{1}{2}$ is violated by the selected configuration of parameters, majority voting produces a system with a low quality public school and a high quality private school - similar to the one described by Epple and Romano, 1998, in their

\footnotetext{
${ }^{20}$ The average test score for males in Murnane's sample is 13.28, with standard error 7.21. Rescaling this variable in the range $[1,2]$ requires that we multiply the estimated coefficient of the test score by 28.84 .
} 
discussion of US secondary schools - in spite of the fact that the social planner would prefer a high quality public school and a private school with a relatively low education standard.

This difference arises because the majority of students enrols in the public school - or drops out - and has relatively lower ability than the minority of students going to the public and the private school. For the majority of households, the marginal return to a high educational standard in the public school is either zero - because their children drop out - or lower than the marginal cost of attaining and funding the standard. Therefore, they choose a relatively low standard for the public school. The social planner, on the other hand, gives the same weight to all voters, including those of high ability and low income, who favor a higher educational standard in the public school, because their cost of effort and their tax burden is relatively low. Hence, she chooses an educational standard for the public school higher than the standard chosen by the majority of voters. Consequently, the private school chooses a lower standard than in the case of majority voting, thereby reinforcing the social planner's choice, because less able students enrol in the private school, where they face a low educational standard.

\section{Conclusions}

When school quality is measured by the educational standard and attaining the standard requires costly effort, the market for secondary education needs not be a hierarchy with private schools offering better quality than public schools. An alternative configuration, with public schools offering a higher educational standard than private schools, can also exist, in spite of the fact that tuition levied by private schools is strictly positive. In the model presented in this paper, private schools can offer a lower educational standard at a positive price because they attract students with a relatively high cost of effort, who would find the high standards of the public school excessively demanding. Clearly, costly effort is only one possible factor driving this result. Alternatives are that 
private schools provide access to labor market networks, which allow to locate better jobs more easily because of the connections they afford, or that they are "snob" goods, which are consumed because of the reputation they offer (see Corneo and Jeanne, 1997), even if quality is lower than in the public school. In either case, the intuition remains the same: by offering services that are not strictly related to quality, private schools can charge a positive price, offer lower quality than public schools and still make positive profits.

When the educational standard of the public school is chosen by majority voting, we show that the choice between a configuration with high quality public schools and a configuration with high quality private schools depends on the marginal return to the educational standard relative to the marginal cost of setting up the standard. If the gap between the two is large enough, a majority emerges in favor of high quality public schools. We calibrate the model by using micro-econometric evidence from the US and find that, based on the calibrated parameters, majority voting in the US should produce a system with high quality private schools and low quality public schools, as assumed by Epple and Romano, 1998. This system, however, does not correspond to the one preferred by the social planner, and the maximization of a utilitarian welfare function would deliver a different system, with high quality public schools and low quality private schools.

\section{References}

[1] Altonji, J. and Pierret, C., 2001, Employer learning and statistical discrimination, The Quarterly Journal of Economics, 313-348.

[2] Blackburn, M. and Neumark, D., Omitted ability bias and the increase in the return to schooling, Journal of Labor Economics, 11, 3, 521-544

[3] Bowles, S., Gintis, H. and M.Osborne, 2001, The determinants of earnings: a behavioral approach, Journal of Economic Literature, 39, 1137-76 
[4] Corneo, G. and Jeanne, O., 1997, Snobs, bandwagons and the origins of social customs in consumer behavior, Journal of Economic Behavior and Organization, 32, 333-347.

[5] Costrell, R. (1994), A Simple Model of Educational Standards, The American Economic Review, 956-971.

[6] De Fraja, G., 2002, The Design of Optimal Education Policies, The Review of Economic Studies, 69, 437-466

[7] De Fraja, G., 2004, Private and public schools: theoretical considerations, in Checchi, D. and Lucifora, C. (eds.), 2004, Education, Training and Labour market outcomes in Europe, Palgrave, London.

[8] Epple, D. and Romano, R., 1998, Competition between private and public schools, vouchers and peer group effects, The American Economic Review, $33 / 62$.

[9] Feinstein, L. and Symons, J., 1999, Attainment in secondary schools, $O x$ ford Economic Papers, 51, 300-321.

[10] Fernandez, R. and Rogerson, R., 1995, On the political economy of education subsidies, The Review of Economic Studies, 62, 249-62.

[11] Figlio, D. and Stone, J., 1997, School choice and student performance > are private schools really better? Institute for Research on Poverty Discussion Paper 1141

[12] Hanushek, E., 2002, Publicly provided education, in Auerbach, A. and Feldstein, M., (eds), Handbook of Public Economics, Amsterdam, Elsevier, 2045-2141.

[13] Hanushek, E. and Kimko, D., 2000, Schooling, labor foce quality and the growth of natiuons, The American Economic Review, 90, 5, 1184-1208. 
[14] McEwan, P., 2000, Comparing the effectiveness of public and private schools: a review of evidence and interpretations, Occasional paper n.3, Teachers College, Columbia University.

[15] Minter Hoxby, C., 2001, School choice and school productivity (or could school choice be a tide that lifts all boats?), NBER working paper.

[16] Murnane, R., Willett, J. and Levy, F., 1995, The growing importance of cognitive skills in wage determination, The Review of Economics and Statistics, 77, 2, 251-266.

[17] Stiglitz, J., 1974, The demand for education in public and private school systems, Journal of Public Economics, 3, 349-385.

[18] Vandenberghe, V. and Robin, S., 2004, Evaluating the effectiveness of private education across countries: a comparison of methods, Labour Economics, 11, 487-506 


\section{Appendix}

\section{Proof of Proposition 1}

First recall that $\pi_{H} \equiv 0$ for $s_{G}>\bar{s}_{G}$ and $\pi_{L} \equiv 0$ for $s_{G}<\underline{s}_{G}$. Next define $\Delta=\pi_{L}-\pi_{H}$. Clearly, when $\Delta>0$ the private school chooses to provide a quality lower than the public school, and viceversa when $\Delta<0$. To study the sign of $\Delta$, consider its derivative with respect to $s_{G}$, i.e. $\frac{\partial \Delta}{\partial s_{G}}=\frac{\partial \pi_{L}}{\partial s_{G}}-\frac{\partial \pi_{H}}{\partial s_{G}}$. Notice that

$$
\frac{\partial \pi_{H}}{\partial s_{G}}\left\{\begin{array}{ccc}
<0 & \text { for } & s_{G}<\bar{s}_{G} \\
=0 & & \text { otherwise }
\end{array}\right.
$$

Next,

$$
\frac{\partial \pi_{L}}{\partial s_{G}}=\left\{\begin{array}{lrr}
>0 & \text { for } & s_{G}>\underline{s}_{G} \\
0 & \text { otherwise }
\end{array}\right.
$$

Summing up, $\Delta=\pi_{L}-\pi_{H}$ is strictly increasing in $s_{G}$. Moreover, $\Delta<0$ for $s_{G}<\underline{s}_{G}$ because $\pi_{L} \equiv 0$ and $\pi_{H}>0$. Symmetrically, $\Delta>0$ for $s_{G}>\bar{s}_{G}$ because $\pi_{L}>0$ and $\pi_{H} \equiv 0$. Therefore, since $\Delta$ is strictly increasing and continuous, there exists a unique value $\underline{s}_{G}<s_{G}^{*}<\bar{s}_{G}$ such that for any $s_{G}>s_{G}^{*}$ the private school chooses a standard below $s_{G}$ and for any $s_{G}<s_{G}^{*}$ the private school chooses a standard above $s_{G}$.

\section{Proof of Proposition 2}

The derivatives $\frac{\partial \pi_{L}}{\partial s_{G}}$ and $\frac{\partial \pi_{H}}{\partial s_{G}}$ are as shown in the proof of Proposition 1. As above, $\pi_{H} \equiv 0$ for $s_{G}>\bar{s}_{G}$ and $\pi_{L} \equiv 0$ for $s_{G}<\underline{s}_{G}$. In this case, however, the difference $\Delta=\pi_{L}-\pi_{H}$ is only weakly increasing in $s_{G}$. First, $\Delta<0$ for $s_{G}<\bar{s}_{G}<\underline{s}_{G}$ because $\pi_{L} \equiv 0$ and $\pi_{H}>0$, which makes high quality preferable by the entrant private school. Second, $\Delta>0$ for $\bar{s}_{G}<\underline{s}_{G}<s_{G}$ because $\pi_{L}>0$ and $\pi_{H} \equiv 0$, so low quality is preferred. Finally $\Delta \equiv 0$ for $\bar{s}_{G}<s_{G}<\underline{s}_{G}$ because simultaneously both $\pi_{L} \equiv 0$ and $\pi_{H} \equiv 0$. In such a region entry is never profitable. 


\section{Proof of Lemma 3}

Since individual ability is distributed in the interval $[0,1]$, as shown in Figure 4 , we need to examine in some detail how households vote.

- individuals with $\theta \in\left[0, \lambda_{1}+\frac{p}{s_{G}-s_{P}}=\lambda_{1}+\frac{\lambda_{0}}{2 s_{G}}\right]$ - areas $\mathrm{C}$ and $\mathrm{D}$ in the figure - choose to enrol in the public school. Therefore, those with $\theta<\lambda_{1}-2 k y$ vote for $s_{G}=2$, and those with $\lambda_{1}-2 k y<\theta<\lambda_{1}+\frac{p}{s_{G}-s_{P}}$ vote for $s_{G}=s_{G}^{*}$. Marginal individuals with $\theta=\lambda_{1}-2 k y$ are indifferent. As shown in Figure 4, the separating segment $\theta=\lambda_{1}-2 k y$ completely belongs to the public school region.

- Individuals with $\theta \in\left[\lambda_{1}+\frac{p}{s_{G}-s_{P}}, \lambda_{1}+\frac{\lambda_{0}\left(s_{G}+1\right)}{2 s_{G}}\right]$ - area B in the figure prefer the private school and vote for $s_{G}=s_{G}^{*}$. Consider now the individual $\theta=\lambda_{1}+\frac{\lambda_{0}\left(s_{G}+1\right)}{2 s_{G}}$. Since her utility is equal to $y(1-\tau)+\lambda_{2} \theta+\lambda_{3} y+\lambda_{4} X$, she is indifferent between participating to upper secondary education and not participating.

- Individuals with $\theta \in\left[\lambda_{1}+\frac{\lambda_{0}\left(s_{G}+1\right)}{2 s_{G}}, 1\right]$ - area $\mathrm{A}$ in the figure - do not participate. Since their utility $\bar{U}=y\left(1-2 k s_{G}\right)+\lambda_{2} \theta+\lambda_{3} y+\lambda_{4} X$ is decreasing in $s_{G}$, they vote for $s_{G}=s_{G}^{*}$

\section{Proof of Lemma 4}

As shown in Figure 5, voting occurs as follows:

- individuals with $\theta \in\left[0, \lambda_{1}-\frac{p}{s_{P}-s_{G}}=\frac{\lambda_{1}}{2}\right]$ - area D in the figure - choose the private school and votes $s_{G}=s_{G}^{*}$, because their utility is strictly increasing in $s_{G}$.

- Individuals with $\theta \in\left[\frac{\lambda_{1}}{2}, \lambda_{1}+\frac{\lambda_{0}}{s_{G}}\right]$ - areas B and $\mathrm{C}$ in the figure - choose the public school. Those with $\frac{\lambda_{1}}{2}<\theta<\lambda_{1}$ vote $s_{G}=s_{G}^{*}$, and those with $\lambda_{1}<\theta<\lambda_{1}+\frac{\lambda_{0}}{s_{G}}$ vote $s_{G}=1$. Clearly, the marginal individuals $\theta=\lambda_{1}-2 k y$ are indifferent. Figure 5 shows that the separating segment 


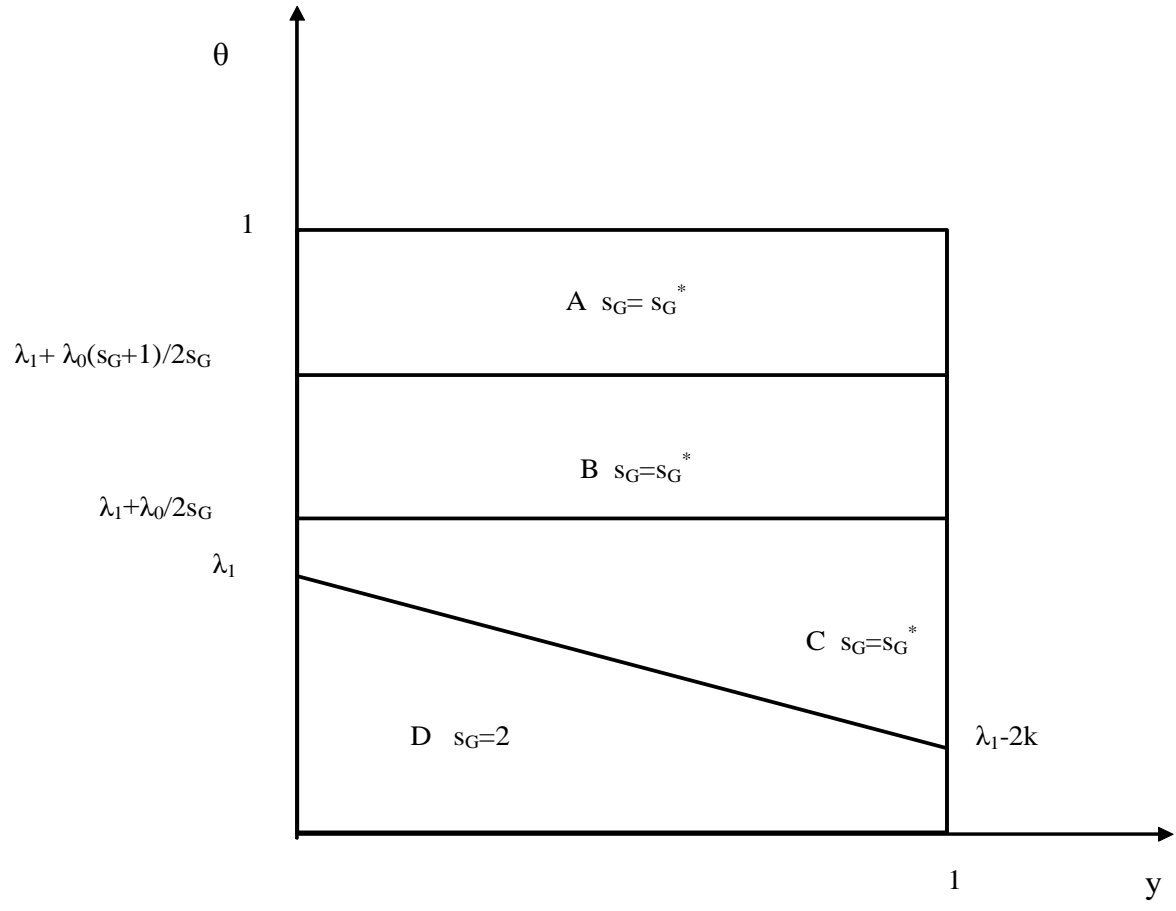

Figure 4: A: no participation; B: private school; C and D: public school 


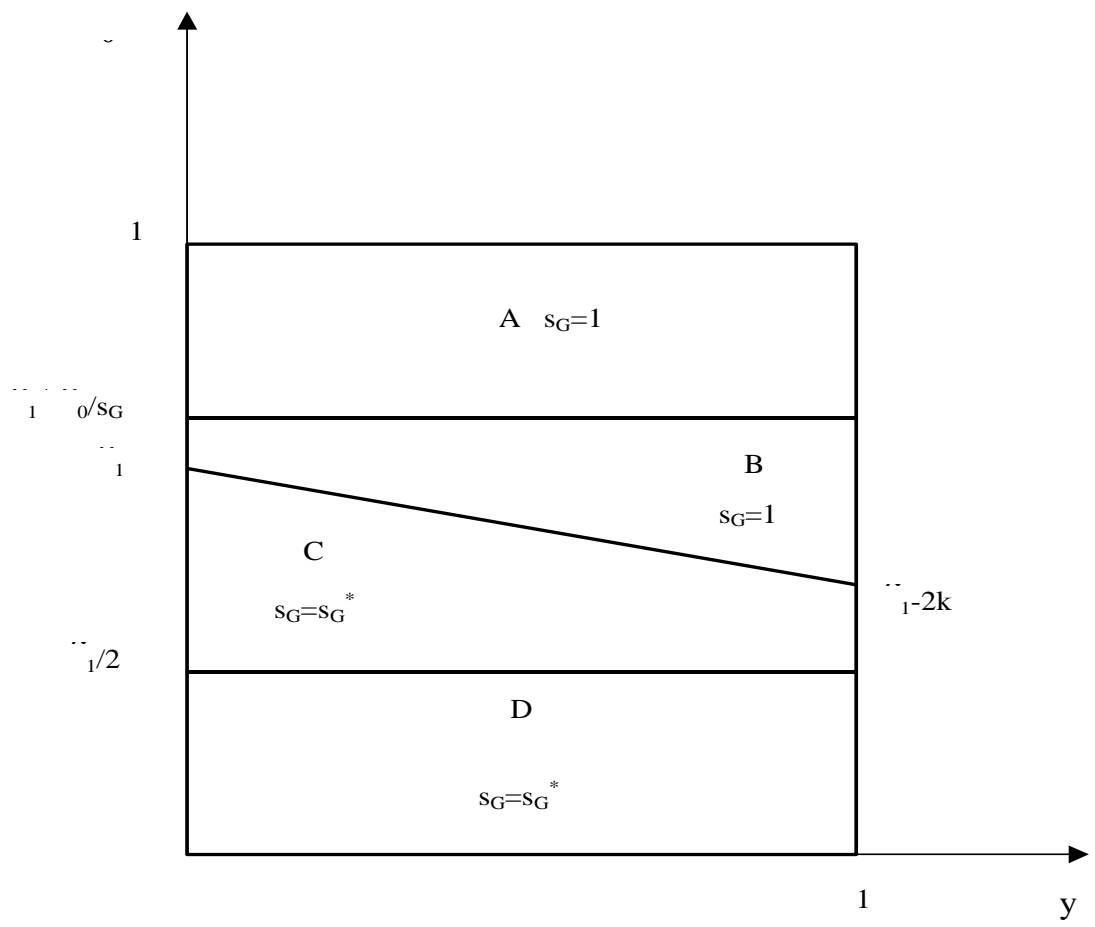

Figure 5: A: no participation; B and C: public school; D: private school

$\lambda_{1}-2 k y$ completely belongs to the region of people choosing the public school, as in the previous regime.

- Finally, individuals with $\theta \in\left[\lambda_{1}+\frac{\lambda_{0}}{s_{G}}, 1\right]$ - area A - do non participate to upper secondary school and vote for the minimum value of $s_{G}$, i.e. $s_{G}=1$.

\section{Proof of Proposition 5}

The marginal individuals $\theta=\lambda_{1}-2 k y$ go to the public school in either regime and have utility

$$
\begin{aligned}
U_{G} & =y\left(1-2 k s_{G}\right)+\lambda_{0}+\lambda_{1} s_{G}+\lambda_{2} \theta+\lambda_{3} y+\lambda_{4} X-\left(\lambda_{1}-2 k y\right) s_{G} \\
& =y+\lambda_{0}+\lambda_{2} \theta+\lambda_{3} y+\lambda_{4} X
\end{aligned}
$$


- independent of $s_{G}$. Consider the individual with $\theta=\lambda_{1}-2 k y-\varepsilon$, where $\varepsilon>0$ is small. Her utility is increasing in $s_{G}$, since

$$
\frac{\partial U_{G}}{\partial s_{G}}=\varepsilon>0
$$

Therefore she prefers the regime with $s_{G}=2$ to the regime with $s_{G}=s_{G}^{*}$. The same choice is taken by individuals with $\theta<\lambda_{1}-2 k y$, who select the public school in both regimes. When $\varepsilon$ is large enough, however, we can have individuals who enrol in the private school if $s_{G}<s_{G}^{*}$ and in the public school if $s_{G}>s_{G}^{*}$. In the private school utility is $U_{P}=y+\lambda_{0}+\lambda_{2} \theta+\lambda_{3} y+\lambda_{4} X+$ $2 \varepsilon-\left(\lambda_{1}-4 k y\right)\left(1-\frac{s_{G}^{*}}{2}\right)$, which is certainly lower than the utility attainable by going to the public school in the regime $s_{G}>s_{G}^{*}$ if $\lambda_{1}^{2}>8 k$, as we have assumed above ${ }^{21}$. Therefore, this individual also chooses the latter regime. We conclude that, if the group with $\theta<\lambda_{1}-2 k y$ is the majority, the optimal choice is $s_{G}=2$.

If the group with $\theta<\lambda_{1}-2 k y$ is not the majority, the regime $s_{G}>s_{G}^{*}$ implies $s_{G}=s_{G}^{*}$ and the regime $s_{G}<s_{G}^{*}$ implies $s_{G}=1$. As above, consider the individual with $\theta=\lambda_{1}-2 k y+\varepsilon$. Since she is in the public school in both regimes, her utility is

$$
U_{G}=y\left(1-2 k s_{G}\right)+\lambda_{0}+\lambda_{1} s_{G}+\lambda_{2} \theta+\lambda_{3} y+\lambda_{4} X-\left(\lambda_{1}-2 k y+\varepsilon\right) s_{G}
$$

which is decreasing in $s_{G}$, since

$$
\frac{\partial U_{G}}{\partial s_{G}}=-\varepsilon<0
$$

Therefore she prefers the regime with $s_{G}=1$ to the regime with $s_{G}=s_{G}^{*}$. As in the previous case, the ordering does not change if the individual belongs to the private school in one regime and to the public school in the other regime. Therefore, when the group with $\theta>\lambda_{1}-2 k y$ is the majority, the optimal choice is $s_{G}=1$.

\section{The case of no high quality private schools}

\footnotetext{
${ }^{21}$ Utility in this regime is $U_{G}=y+\lambda_{0}+2 \varepsilon+\lambda_{2} s_{G}+\lambda_{3} \theta+\lambda_{4} X$
} 
As in the previous section we analyze voting in the two regimes and compare outcomes across regimes. If the public standard is higher than $\underline{s}_{G}$, we are back to Figure 4 , with the exception that the critical value $s_{G}^{*}$ is now $\underline{s}_{G}$. While individuals with $\theta<\lambda_{1}-2 k y$ vote for $s_{G}=2$, the rest vote for $s_{G}=\underline{s}_{G}$. There are two sub-cases: 1 ) when $\lambda_{1}-2 k>0$, the analysis conducted above still carries on, and the size of the group choosing $s_{G}=2$ is $\left.\lambda_{1}-k ; 2\right)$ when $\lambda_{1}-2 k<0$, the segment $\theta=\lambda_{1}-2 k y$ in Figure 4 cuts the horizontal axis at $y=\frac{\lambda_{1}}{2 k}$ and the size of the group voting for $s_{G}=2$ is $\frac{\lambda_{1}^{2}}{4 k}$, lower that $\frac{1}{2}$ by assumption. In this case the majority votes for $s_{G}^{*}$.

When $s_{G}$ is below $\underline{s}_{G}$ the private school does not enter and individuals can only choose between the public school and no participation. The corresponding voting map is as in Figure 5 with the exception that $s_{G}^{*}$ is now equal to $\underline{s}_{G}$ and that anyone with $\theta<\frac{\lambda_{1}}{2}$ necessarily chooses the public school. In this case, individuals with $\theta<\lambda_{1}-2 k y$ vote for $s_{G}=\underline{s}_{G}$ and the rest vote for $s_{G}=1$. As in the previous regime, we have two sub-cases and the same argument applies, with the majority choosing either $s_{G}=s_{G}^{*}$ or $s_{G}=1$.

Suppose first that the group formed by those with $\theta<\lambda_{1}-2 k y$ is the majority, and take the near-to-the-marginal individual $\theta=\lambda_{1}-2 k y-\varepsilon$. As shown in the proof of Proposition 5, her utility is increasing in $s_{G}$. Hence she prefers $s_{G}=2$. Conversely, if the group formed by those with $\theta>\lambda_{1}-2 k y$ is the majority, the corresponding near-to-the marginal individual prefers $s_{G}=1$, and so does the majority.

\section{The case of no low quality private schools}

The case with the private school is illustrated in Figure 5 with $s_{G}^{*}$ replaced by $\bar{s}_{G}$. The case of no entry by the private school is illustrated in Figure 4 with the cautionary note that individuals can only choose between a public school and no school at all. Hence the cutoff point separating the individuals who participate from the non participating individuals is $\theta=\lambda_{1}+\frac{\lambda_{0}}{s_{G}}$ rather than $\theta=\lambda_{1}+\frac{\lambda_{0}\left(s_{G}+1\right)}{2 s_{G}}$.

The group with $\theta<\lambda_{1}-2 k y$ has always size $\lambda_{1}-k$ and chooses $s_{G}=\bar{s}_{G}$ 
when the private school enters the market and $s_{G}=2$ when there is only the public school. In these cases the group with $\theta>\lambda_{1}-2 k y$ chooses $s_{G}=1$ and $s_{G}=\bar{s}_{G}$ respectively. Comparing the two regimes, the near-to-the-marginal individual $\theta=\lambda_{1}-2 k y-\varepsilon$ (belonging to the first group) prefers $s_{G}=2$ (since her utility is increasing in $s_{G}$ ), and the the near-to-the-marginal individual $\theta=\lambda_{1}-2 k y+\varepsilon$ (belonging to the second group) prefers $s_{G}=1$. Therefore, if the majority condition $\lambda_{1}-k>\frac{1}{2}$ holds, the voting outcome is $s_{G}=2$, and a school system characterized by an excellent public school with no private schools prevails. Conversely, if $\lambda_{1}-k<\frac{1}{2}$, then $s_{G}=1$.

The case $\underline{s}_{G}>\bar{s}_{G}$

The solution of this case closely follows the procedure used in the main text. We find it useful to distinguish between three regimes: 1) $s_{G}>\underline{s}_{G}$, with the private school having a low standard; 2) $s_{G}<\bar{s}_{G}$, with the private school having a high standard; and 3) $\bar{s}_{G}<s_{G}<\underline{s}_{G}$, with no entry by the private school.

The first regime parallels the case $s_{G}>s_{G}^{*}$ discussed in the text, provided that we substitute $s_{G}^{*}$ with $\underline{s}_{G}$. If the group of individuals with $\theta<\lambda_{1}-2 k y$ is the majority, the optimal choice is $s_{G}=2, s_{P}=1$ and $p=\frac{1}{4} \lambda_{0}$. If instead the group $\theta>\lambda_{1}-2 k y$ is the majority, the optimal choice is $s_{G}=\underline{s}_{G}, s_{P}=1$ and $p=\frac{1}{2} \frac{\lambda_{0}\left(\underline{s}_{G}-1\right)}{\underline{s}_{G}}$

The second regime parallels the case $s_{G}<s_{G}^{*}$ discussed in the text, provided that we substitute $s_{G}^{*}$ with $\bar{s}_{G}$. If the group of individuals with $\theta<\lambda_{1}-2 k y$ is the majority, the optimal choice is $s_{G}=\bar{s}_{G}$, and in equilibrium $s_{P}=2$ and $p=\frac{\left(2-\bar{s}_{G}\right) \lambda_{1}}{2}$. If instead the group $\theta>\lambda_{1}-2 k y$ is the majority, the optimal choice is $s_{G}=1$, and in equilibrium $s_{P}=2$ and $p=\frac{\lambda_{1}}{2}$.

Finally, when $\bar{s}_{G}<s_{G}<\underline{s}_{G}$ the private school does not enter and individuals can only choose between the public school and no participation. The corresponding voting map is as in Figure 4 in the text, with the exception that $s_{G}^{*}$ is now equal to $\underline{s}_{G}, s_{G}=1$ is replaced by $s_{G}=\bar{s}_{G}$ and that anyone with $\theta<\frac{\lambda_{1}}{2}$ necessarily chooses the public school. In this case, individuals with $\theta<\lambda_{1}-2 k y$ vote for $s_{G}=\underline{s}_{G}$ and the rest vote for $s_{G}=\bar{s}_{G}$. 
The choice between regimes is determined by the preferences of the near-tomarginal individuals. Suppose that $\theta<\lambda_{1}-2 k y$ is the majority and consider the individual with $\theta=\lambda_{1}-2 k y-\varepsilon$. We have already seen that her utility is increasing in $s_{G}$. Hence, when facing the options $s_{G}=2, s_{G}=\bar{s}_{G}$ and $s_{G}=\underline{s}_{G}$ corresponding to the three regimes, she will prefer $s_{G}=2$, as in the "regular" $\underline{s}_{G}<\bar{s}_{G}$ case. Suppose now that $\theta>\lambda_{1}-2 k y$ is the majority and take the individual $\theta=\lambda_{1}-2 k y+\varepsilon$, whose utility is decreasing in $s_{G}$. When facing the options $s_{G}=\underline{s}_{G}, s_{G}=1$ and $s_{G}=\bar{s}_{G}$, she will prefer $s_{G}=1$, as in the "regular" $\underline{s}_{G}<\bar{s}_{G}$ case.

Summarizing, the voting outcome does not change when the order of the profitability thresholds $\underline{s}_{G}$ and $\bar{s}_{G}$ is reversed. Moreover, the regime of no entry is never preferred by the voters. 


\title{
CESifo Working Paper Series
}

\author{
(for full list see www.cesifo.de)
}

1354 Matteo Governatori and Sylvester Eijffinger, Fiscal and Monetary Interaction: The Role of Asymmetries of the Stability and Growth Pact in EMU, December 2004

1355 Fred Ramb and Alfons J. Weichenrieder, Taxes and the Financial Structure of German Inward FDI, December 2004

1356 José Luis Moraga-González and Jean-Marie Viaene, Dumping in Developing and Transition Economies, December 2004

1357 Peter Friedrich, Anita Kaltschütz and Chang Woon Nam, Significance and Determination of Fees for Municipal Finance, December 2004

1358 M. Hashem Pesaran and Paolo Zaffaroni, Model Averaging and Value-at-Risk Based Evaluation of Large Multi Asset Volatility Models for Risk Management, December 2004

1359 Fwu-Ranq Chang, Optimal Growth and Impatience: A Phase Diagram Analysis, December 2004

1360 Elise S. Brezis and François Crouzet, The Role of Higher Education Institutions: Recruitment of Elites and Economic Growth, December 2004

1361 B. Gabriela Mundaca and Jon Strand, A Risk Allocation Approach to Optimal Exchange Rate Policy, December 2004

1362 Christa Hainz, Quality of Institutions, Credit Markets and Bankruptcy, December 2004

1363 Jerome L. Stein, Optimal Debt and Equilibrium Exchange Rates in a Stochastic Environment: an Overview, December 2004

1364 Frank Heinemann, Rosemarie Nagel and Peter Ockenfels, Measuring Strategic Uncertainty in Coordination Games, December 2004

1365 José Luis Moraga-González and Jean-Marie Viaene, Anti-Dumping, Intra-Industry Trade and Quality Reversals, December 2004

1366 Harry Grubert, Tax Credits, Source Rules, Trade and Electronic Commerce: Behavioral Margins and the Design of International Tax Systems, December 2004

1367 Hans-Werner Sinn, EU Enlargement, Migration and the New Constitution, December 2004

1368 Josef Falkinger, Noncooperative Support of Public Norm Enforcement in Large Societies, December 2004 
1369 Panu Poutvaara, Public Education in an Integrated Europe: Studying to Migrate and Teaching to Stay?, December 2004

1370 András Simonovits, Designing Benefit Rules for Flexible Retirement with or without Redistribution, December 2004

1371 Antonis Adam, Macroeconomic Effects of Social Security Privatization in a Small Unionized Economy, December 2004

1372 Andrew Hughes Hallett, Post-Thatcher Fiscal Strategies in the U.K.: An Interpretation, December 2004

1373 Hendrik Hakenes and Martin Peitz, Umbrella Branding and the Provision of Quality, December 2004

1374 Sascha O. Becker, Karolina Ekholm, Robert Jäckle and Marc-Andreas Mündler, Location Choice and Employment Decisions: A Comparison of German and Swedish Multinationals, January 2005

1375 Christian Gollier, The Consumption-Based Determinants of the Term Structure of Discount Rates, January 2005

1376 Giovanni Di Bartolomeo, Jacob Engwerda, Joseph Plasmans, Bas van Aarle and Tomasz Michalak, Macroeconomic Stabilization Policies in the EMU: Spillovers, Asymmetries, and Institutions, January 2005

1377 Luis H. R. Alvarez and Erkki Koskela, Progressive Taxation and Irreversible Investment under Uncertainty, January 2005

1378 Theodore C. Bergstrom and John L. Hartman, Demographics and the Political Sustainability of Pay-as-you-go Social Security, January 2005

1379 Bruno S. Frey and Margit Osterloh, Yes, Managers Should Be Paid Like Bureaucrats, January 2005

1380 Oliver Hülsewig, Eric Mayer and Timo Wollmershäuser, Bank Loan Supply and Monetary Policy Transmission in Germany: An Assessment Based on Matching Impulse Responses, January 2005

1381 Alessandro Balestrino and Umberto Galmarini, On the Redistributive Properties of Presumptive Taxation, January 2005

1382 Christian Gollier, Optimal Illusions and Decisions under Risk, January 2005

1383 Daniel Mejía and Marc St-Pierre, Unequal Opportunities and Human Capital Formation, January 2005

1384 Luis H. R. Alvarez and Erkki Koskela, Optimal Harvesting under Resource Stock and Price Uncertainty, January 2005 
1385 Ruslan Lukach, Peter M. Kort and Joseph Plasmans, Optimal R\&D Investment Strategies with Quantity Competition under the Threat of Superior Entry, January 2005

1386 Alfred Greiner, Uwe Koeller and Willi Semmler, Testing Sustainability of German Fiscal Policy. Evidence for the Period 1960 - 2003, January 2005

1387 Gebhard Kirchgässner and Tobias Schulz, Expected Closeness or Mobilisation: Why Do Voters Go to the Polls? Empirical Results for Switzerland, 1981 - 1999, January 2005

1388 Emanuele Bacchiocchi and Alessandro Missale, Managing Debt Stability, January 2005

1389 Assar Lindbeck and Dirk Niepelt, Improving the SGP: Taxes and Delegation rather than Fines, January 2005

1390 James J. Heckman and Dimitriy V. Masterov, Skill Policies for Scotland, January 2005

1391 Emma Galli \& Fabio Padovano, Sustainability and Determinants of Italian Public Deficits before and after Maastricht, January 2005

1392 Angel de la Fuente and Juan Francisco Jimeno, The Private and Fiscal Returns to Schooling and the Effect of Public Policies on Private Incentives to Invest in Education: A General Framework and Some Results for the EU, January 2005

1393 Juan C. Conesa and Carlos Garriga, Optimal Response to a Demographic Shock, January 2005

1394 Christian Gollier, Optimal Portfolio Management for Individual Pension Plans, February 2005

1395 Ruslan Lukach, Joseph Plasmans and Peter M. Kort, Innovation Strategies in a Competitive Dynamic Setting, February 2005

1396 Gebhard Kirchgässner, (Why) Are Economists Different?, February 2005

1397 Marko Köthenbürger, Panu Poutvaara and Paola Profeta, Why are More Redistributive Social Security Systems Smaller? A Median Voter Approach, February 2005

1398 Gabrielle Demange, Free Choice of Unfunded Systems: A First Assessment, February 2005

1399 Carlos Fonseca Marinheiro, Sustainability of Portuguese Fiscal Policy in Historical Perspective, February 2005

1400 Roel M. W. J. Beetsma and Koen Vermeylen, The Effect of Monetary Unification on Public Debt and its Real Return, February 2005

1401 Frank Asche, Petter Osmundsen and Maria Sandsmark, Is It All Oil?, February 2005 
1402 Giacomo Corneo, Media Capture in a Democracy: The Role of Wealth Concentration, February 2005

1403 A. Lans Bovenberg and Thijs Knaap, Ageing, Funded Pensions and the Dutch Economy, February 2005

1404 Thiess Büttner, The Incentive Effect of Fiscal Equalization Transfers on Tax Policy, February 2005

1405 Luisa Fuster, Ayşe İmrohoroğlu and Selahattin İmrohoroğlu, Personal Security Accounts and Mandatory Annuitization in a Dynastic Framework, February 2005

1406 Peter Claeys, Policy Mix and Debt Sustainability: Evidence from Fiscal Policy Rules, February 2005

1407 James M. Malcomson, Supplier Discretion over Provision: Theory and an Application to Medical Care, February 2005

1408 Thorvaldur Gylfason, Interview with Assar Lindbeck, February 2005

1409 Christian Gollier, Some Aspects of the Economics of Catastrophe Risk Insurance, February 2005

1410 Gebhard Kirchgässner, The Weak Rationality Principle in Economics, February 2005

1411 Carlos José Fonseca Marinheiro, Has the Stability and Growth Pact Stabilised? Evidence from a Panel of 12 European Countries and Some Implications for the Reform of the Pact, February 2005

1412 Petter Osmundsen, Frank Asche, Bård Misund and Klaus Mohn, Valuation of International Oil Companies -The RoACE Era, February 2005

1413 Gil S. Epstein and Shmuel Nitzan, Lobbying and Compromise, February 2005

1414 Marcel F. M. Canoy, Jan C. van Ours and Frederick van der Ploeg, The Economics of Books, February 2005

1415 Eric A. Hanushek and Ludger Wößmann, Does Educational Tracking Affect Performance and Inequality? Differences-in-Differences Evidence across Countries, February 2005

1416 George Kapetanios and M. Hashem Pesaran, Alternative Approaches to Estimation and Inference in Large Multifactor Panels: Small Sample Results with an Application to Modelling of Asset Returns, February 2005

1417 Samuel Mühlemann, Jürg Schweri, Rainer Winkelmann and Stefan C. Wolter, A Structural Model of Demand for Apprentices. February 2005

1418 Giorgio Brunello and Lorenzo Rocco, Educational Standards in Private and Public Schools, February 2005 